\title{
ORIGINAL ARTICLE \\ Acremonium terricola culture plays anti-inflammatory and antioxidant roles by modulating MAPK signaling pathways in rats with lipopolysaccharide-induced mastitis
}

\author{
Yang Li'\#, Xin Jiang'\#, Hongjian Xu', Jingyi Lv', Guangning Zhang', Xiujing Dou'*, Yonggen \\ Zhang ${ }^{*}$ and Xiaoxiang Li \\ 'College of Animal Science and Technology, Northeast Agricultural University, Harbin, China; ${ }^{2}$ Microbial Biological \\ Engineering Company Limited, Hefei, China
}

\begin{abstract}
Popular scientific summary
Acremonium terricola culture (ATC) is a new type of affordable feed additive. ATC plays anti-inflammatory and antioxidant roles in rats with lipopolysaccharide-induced mastitis. ATC pretreatment plays a role in anti-inflammatory action by interfering with TLR4 expression, which subsequently inhibits the downstream MAPK signaling pathways and the release of the pro-inflammatory cytokines.
\end{abstract}

Abstract

Background: As a major disease affecting dairy cow production worldwide, bovine mastitis is caused by a variety of pathogenic microorganisms that eventually cause mammary gland inflammation. Acremonium terricola culture (ATC) is a new type of affordable feed additive produced by the solid fermentation of $A$. terricola isolated from Cordyceps gunnii and exerted its anti-inflammatory effect.

Objectives: To evaluate the protective effects of ATC on mastitis and investigate its active mechanism, a lipopolysaccharide (LPS)-induced rat mastitis model was used in two experiments.

Design: In Experiment 1, a total of 40 female Sprague-Dawley rats were used to determine the optimal supplementary dose of ATC via gavage trial. In Experiment 2, we examined the effects of an optimal dose of ATC on LPS-induced mastitis in rats.

Results: The results of Experiment 1 showed that administration of ATC improved growth performance and antioxidant functions in the serum and the liver, as well as immunoglobulin A, G, and M levels in rat serum, and it decreased the content of alanine aminotransferase, aspartate aminotransferase, triglyceride, cholesterol, low-density lipoprotein, and serum urea nitrogen in rat serum; a dosage of $250-1,250 \mathrm{mg} / \mathrm{kg} / \mathrm{day}$ was shown to be high enough to be effective. The results of Experiment 2 indicated that ATC can relieve the inflammatory reaction of mammary glands in rats, and the LPS-induced expression of tumor necrosis factor- $\alpha$, interleukin-1 $\beta$, interleukin-6, and inducible nitric oxide synthase significantly decreased after ATC treatment. Moreover, our results demonstrated that ATC markedly enhanced the activity of antioxidase in this rat mastitis model. The results of Western blot analysis revealed that ATC could suppress the expression of toll-like receptor 4, phosphorylation of extracellular signal-regulated kinase, and activity of c-Jun N-terminal kinase in the LPS-stimulated mastitis model.

Conclusion: Taken together, ATC was shown to exert its anti-inflammatory effect by blocking mitogen-activated protein kinase signaling pathways. These results demonstrate that ATC exerts anti-inflammatory and antioxidant effects in mastitis prevention.

Keywords: Acrermonium terricola culture; mastitis; anti-inflammation; antioxidant 
A s a major disease affecting dairy cow production worldwide, bovine mastitis is caused by a variety of pathogenic microorganisms that eventually cause mammary gland inflammation (1), consequently causing reduced milk yield and milk quality and increased treatment costs, thereby resulting in economic losses for the dairy industry worldwide (2). In addition to maintaining environmental hygiene, the application of exogenous substances is an important measure for preventing mastitis. Chinese medicines, such as Geniposide and Baicalin, have been extensively used as antibiotic substitutes in the prevention of mastitis $(3,4)$. Cordyceps gunnii has long been used as a health food because of its 'Yin-nourishing' and 'Yang-invigorating' actions as a famous traditional Chinese herbal medicine. In addition, it has attracted much attention due to the presence of anti-inflammatory, antitumor, and immunomodulatory effects (5). However, due to the scarcity and high price of C. gunnii, its development and application in the livestock industry has been limited. Interestingly, Acremonium terricola culture (ATC) is a new and affordable type of feed additive produced by the solid fermentation of $A$. terricola isolated from $C$. gunnii, and its active ingredients and functions are similar to those of natural Cordyceps. Our previous research found that ATC has a wide range of biological functions, such as antioxidant action, immune regulation, and anti-inflammatory activity $(6,7)$. It was reported that ATC significantly decreased somatic cell count (SCC) in milk in our previous study (6). It has been verified that cordycepin included in ATC can attenuate inflammatory cytokine expression in vitro (8). Therefore, it is theoretically feasible for ATC to prevent and treat bovine mastitis.

To make further our understanding of the protective effects of ATC against mastitis, the active mechanism of action of ATC on mammary glands should be studied in more detail using a mastitis model. It is well-known that Escherichia coli is a major pathogen for mastitis. The injection of lipopolysaccharide (LPS), as the critical pathogenic factor of $E$. coli, into a lactating mouse mammary gland via the nipple has been demonstrated to lead to the same syndrome as naturally occurring mastitis caused by E. coli (9). Therefore, in this experiment, a rat mastitis model was established by E. coli LPS breast injection to perform an ATC anti-inflammatory test. Ideally, such experimental infection studies are conducted using dairy cows. Unfortunately, these bovine studies are expensive and labor intensive. For those reasons, a mouse mastitis model was developed and characterized (10) and has since been successfully used for research and to prevent inflammation (11).

It is well-known that Toll-like receptor 4 (TLR4) is indispensable for LPS signaling (12). The TLR4-LPS interaction leads to the rapid and coordinated activation of the mitogen-activated protein kinase (MAPK) signaling pathway, which includes extracellular signal-regulated kinases
(ERK), c-Jun N-terminal kinases (JNK), and p38 kinases, and activates inducible nitric oxide synthase (iNOS) and other pro-inflammatory genes. However, to date, there remain gaps in the understanding of the metabolic pathway of ATC in the treatment of mastitis. Therefore, it was hypothesized that ATC could exert its anti-inflammatory effect by regulating MAPK signaling pathways. To validate the hypothesis of this experiment, two gavage trials were conducted to evaluate the protective effect of ATC against LPS-induced mastitis and to clarify its anti-inflammatory mechanism.

\section{Materials and methods}

\section{Preparation of ATC}

A. terricola is a fungus isolated from the sclerotium of C. gunnii (13). The fungus is deposited under the China Microbial Culture Collection at CGMCC No. 0346. ATC is obtained by artificial solid-state fermentation of the strain by Hefei Micro Biological Engineering Co. Ltd. (Hefei, China). The fermentation method was carried out as follows: A. terricola was inoculated to a solid medium and cultured at a relative humidity of $80-90 \%$ at $25^{\circ} \mathrm{C}$ for $76 \mathrm{~h}$. Subsequently, it was dried at $80^{\circ} \mathrm{C}$ for $1 \mathrm{~h}$. The dried sample was passed through a $0.15 \mathrm{~mm}$ sieve. The solid fermentation medium consisted of $69.9 \%$ corn, $20 \%$ soybean meal, $10 \%$ wheat bran, $0.08 \% \mathrm{KH}_{2} \mathrm{PO}_{4}$, and $0.02 \%$ $\mathrm{MgSO}_{4}$.

ATC contained the following functional ingredients: cordycepin (3'-deoxyadenosine; $0.0432 \%$ of dry matter [DM]), cordycepic acid (d-mannitol; 8.45\% of DM), Cordyceps polysaccharide (galactomannan; $4.46 \%$ of DM), ergosterol ( $0.0597 \%$ of DM), and total amino acid content $(21.81 \%$ of DM). It contained $63.37 \%$ nitrogen-free extract, $24.53 \%$ crude protein (CP), 5.6\% moisture, $5.0 \%$ crude fiber (CF), $4.04 \%$ crude ash, and $3.06 \%$ ether extract (EE).

\section{Animals and housing conditions}

The two experiments were conducted at the Experimental Practice and Demonstration Center of Northeast Agricultural University (Harbin, China). The Sprague-Dawley (SD) rats (40 females used in first experiment; 40 females and 40 males used in second experiment) and the base feed were purchased from Beijing Vital River Laboratory Animal Technology Co., Ltd. (Beijing, China), and all experimental procedures were approved by the Northeast Agricultural University Animal Science and Technology College Animal Care and Use Committee (protocol number: NEAU-[2011]9). The rats were housed in room with free access to rodent chow and water and were kept in an environment with a controlled temperature $\left(23 \pm 1^{\circ} \mathrm{C}\right)$ and humidity $(60 \pm 10 \%)$ under a $12 \mathrm{~h}$ light/dark cycle. All animal experiments were started after 1 week of acclimation. 
Experimental design

\section{Experiment I}

A total of 40 female SD rats (7 weeks old, $165.93 \pm 5.64 \mathrm{~g}$ ) were randomly divided into five groups consisting of eight rats each (treatment group: gastric perfusion of ATC (10, 50,250 , and $1,250 \mathrm{mg} / \mathrm{kg}$ body weight [BW]); control group: gastric perfusion of saline) for 21 days gavage trial.

\section{Experiment 2}

The 40 female rats (7 weeks old, $165.2 \pm 4.82 \mathrm{~g}$ ) were randomly divided into a control group (control), LPS group (LPS), LPS + ATC group (LPS + ATC), and ATC group (ATC). This experiment lasted until 1 week after the birth of their offspring. A female rat and a male rat were kept in one cage for mating for 4 weeks after the experiment began. Throughout the trial period, the rats in LPS + ATC and ATC groups were administered physiological saline $(5 \mathrm{~mL})$ with ATC (250 mg/kg BW) by gavage, seven times per week. Meanwhile, rats in control and LPS groups were administered equal volumes of physiological saline that lacked ATC. The rat mastitis model was established by the injection of LPS $(0.2 \mathrm{mg} / \mathrm{mL}$ LPS $50 \mu \mathrm{L})$ into the mammary ducts of rats from LPS and LPS + ATC on day 7 after the birth of their offspring. Meanwhile, the rats from control and ATC received $50 \mu \mathrm{L}$ of sterile PBS via mammary duct injection.

\section{Sample collection}

\section{Experiment I}

The feed intake was monitored every day for individual rats by weighing the amounts of feed offered and refused daily, BW was measured every 5 days, and then the rats were sacrificed at the end of the study via eyeball extraction (14). Blood was taken from the retro-orbital plexus on day 21 and then centrifuged at $1,200 \times g$ for $10 \mathrm{~min}$; then, the serum was prepared and stored at $-20^{\circ} \mathrm{C}$ for further analysis. After sacrifice, liver sections were immediately excised and rinsed in normal saline. Thereafter, liver tissue homogenates $(10 \%)$ were prepared in chilled normal saline and were then centrifuged at $2,000 \times g$ at $4^{\circ} \mathrm{C}$ for $10 \mathrm{~min}$; thereafter, the supernatants were frozen and preserved at $-20^{\circ} \mathrm{C}$ until evaluation for antioxidant function.

\section{Experiment 2}

The pups were removed from the lactating rats $1 \mathrm{~h}$ before the injection of LPS. The rats were sacrificed at $24 \mathrm{~h}$ after LPS was injected and mammary glands were observed and harvested. One tube of the mammary gland tissue fixed in $10 \%$ formalin was kept at $4^{\circ} \mathrm{C}$ for further histological analysis, and another tube of mammary gland tissue was stored at $-80^{\circ} \mathrm{C}$ to detect cytokine production, antioxidant indices, iNOS and TLR4 expressions, and the MAPK signaling pathway.

\section{Chemical analyses}

\section{Nutrient composition of ATC}

The contents of ergosterol, cordycepin, and cordycepic acid, and Cordyceps polysaccharide in ATC were determined by high-performance liquid chromatography (15). The amino acid content was determined using a HITACHI L-8800 automatic amino acid analyzer (HITACHI Co., Tokyo, Japan). The DM (method 930.15), CF (method 993.21), crude ash (method 942.05), EE (method 920.39), and CP (method 976.05) were analyzed according to the methods of the Association of Official Analytical Chemists (16).

\section{Experiment I}

The serum total protein, alkaline phosphatase, urea nitrogen, alanine transaminase (ALT), aspartate transaminase (AST), cholesterol, triglyceride, high-density lipoprotein, and low-density lipoprotein levels were analyzed with a fully automatic biochemical analyzer using standard commercial kits supplied from Biosino Biotec (Beijing, China). The concentrations of immunoglobulin A, M, and $\mathrm{G}$ in the serum were analyzed using enzyme-linked immunosorbent assay (ELISA) kits (R\&D Systems, Minneapolis, MN, USA). The catalase, glutathione peroxidase, total superoxide dismutase, total antioxidant capacity, and malonaldehyde levels in the serum and liver tissue were determined by colorimetry using standard commercial kits (Nanjing Jian Cheng Bioengineering Institute, Nanjing, China). The enzyme activity and total antioxidant capacity levels were expressed as units/mg of protein.

Experiment 2The samples of mammary gland in each group were fixed in formaldehyde for $24 \mathrm{~h}$, and then the fixed tissues were embedded in paraffin, sliced and stained with hematoxylin and eosin (H\&E). The histopathological changes of mammary gland tissues were observed by microscope (Olympus, Japan).

The mRNA levels of interleukin-1 $\beta$ (IL-1 $\beta$ ), tumor necrosis factor- $\alpha$ (TNF- $\alpha$ ), and interleukin-6 (IL-6) in mammary glands were measured using quantitative real-time PCR (qRT-PCR). Total RNA was extracted using Trizol according to the manufacturer's instructions. Then, cDNA was synthesized according to the manufacturer's instructions (RR037, Takara, Japan) (16). qRT-PCR was performed to measure the levels of mRNA using the SYBR Green Plus reagent kit (RR420, Takara, Japan) and a 7500 Fast Real-time PCR System (Applied Biosystems, USA) (10). The PCR primer sets used are shown in Table 1. Relative gene expression of mRNA was calculated using the $2^{-\Delta \Delta C t}$ method, with $\beta$-actin as the reference gene (17).

To determine the production of cytokines more accurately, the content of pro-inflammatory cytokines was determined by ELISA. Total protein of mammary gland tissues was extracted using the M-PER Mammalian Protein Extraction 


\begin{tabular}{|c|c|c|c|}
\hline \multirow[t]{2}{*}{ Gene } & Forward primer (from 5' to 3') & \multirow[t]{2}{*}{ Fragment length (bp) } & \multirow[t]{2}{*}{ Genbank no. } \\
\hline & Reverse primer (from 5' to 3') & & \\
\hline \multirow[t]{2}{*}{ IL-I $\beta$} & AAAAATGCCTCGTGCTGTCT & 118 & NM_03I5I2.2 \\
\hline & TCGTTGCTTGTCTCTCCTTG & & \\
\hline \multirow[t]{2}{*}{ IL-6 } & AGTTGCCTTCTTGGGACTGA & 102 & NM_0I 2589.2 \\
\hline & ACTGGTCTGTTGTGGGTGGT & & \\
\hline \multirow[t]{2}{*}{ TNF- $\alpha$} & GTCGTAGCAAACCACCAAGC & 147 & NM_0I 2675.3 \\
\hline & GAAGAGAACCTGGGAGTAGATAAGG & & \\
\hline \multirow{2}{*}{$\beta$-Actin } & GCTCTCTTCCAGCCTTCCTT & 101 & NM_03II44.3 \\
\hline & AGGTCTTTACGGATGTCAACG & & \\
\hline
\end{tabular}

RT-PCR, real-time PCR.

Reagent (Thermo Scientific, Waltham, MA, USA). The concentration of protein was measured using the Bicinchoninic Acid (BCA) method. The levels of TNF- $\alpha$, IL-6, and IL-1 $\beta$ in mammary glands were measured using ELISA (BOSTER, Wuhan, China) according to the manufacturer's recommendations. The mammary gland tissues were homogenized in PBS (1:9, w/v). Afterward, the homogenate was centrifuged twice at $2,000 \times g$ to remove the lipids. In addition, total antioxidant capacity, glutathione peroxidase, total superoxide dismutase, malonaldehyde, and catalase levels in mammary glands were measured by colorimetry using standard commercial kits (Nanjing, China).

For the Western blot analysis, $50 \mu \mathrm{g}$ samples of denatured protein lysates were loaded on polyacrylamide gels $(10 \%)$ and transferred onto Polyvinylidene Fluoride (PVDF). membranes. Then, the membranes were blocked with 5\% skimmed milk in Tris Buffered Saline with Tween (TBST) for $2 \mathrm{~h}$ at $37^{\circ} \mathrm{C}$ before incubation with primary antibodies in TBST overnight at $4^{\circ} \mathrm{C}$ in $1 \%$ BSA. Reprobing with a secondary Horseradish Peroxidase (HRP)-conjugated antibody was performed for $1 \mathrm{~h}$ at room temperature. The antibodies used were anti-p38 MAPK, anti-p-p38 MAPK, anti-ERK, antip-ERK, anti-JNK, anti-p-JNK, anti-TLR4, and anti-iNOS, and $\beta$-actin was used as a control. Finally, blots were visualized using the ECL plus Western blot detection system. The expression of each protein was normalized to $\beta$-actin. The images were captured using an ImageLab developing system (DNR Bio-Imaging Systems, Jerusalem, Israel).

\section{Statistical analysis}

Data were analyzed using ANOVA with SAS software, and Duncan's multiple range test was used for both experiments. The data are expressed as means \pm standard error of the mean, and statistical significance was defined at $P<0.05$.

\section{Results}

\section{Effects of ATC on growth performance in rats}

There is no difference among the treatments for dry matter intake (data not shown). Additionally, as shown in Fig. 1, no significant differences were found in BW $(P=0.14)$ at the start of the experiment. The BWs of the treatment group from day 9 were higher than those of the control group, and the highest $\mathrm{BW}$ was seen $(P<0.01)$ in the 250 $\mathrm{mg} / \mathrm{kg}$ treatment group. Compared with the control group, ATC supplementation markedly increased average daily gain $(P<0.0001)$, the highest average daily gain was seen in the $250 \mathrm{mg} / \mathrm{kg}$ treatment, and average daily gain was not significantly different among the other test groups (Fig. 2).

\section{Effects of ATC on serum biochemical and immune indicators} in rats

Serum parameters are shown in Table 2. Compared with the control group, the activity of AST $(P=0.0004)$ and ALT $(P<0.0001)$, and contents of cholesterol $(P=0.0005)$, SUN $(P=0.0002)$, low-density lipoprotein $(P<0.0001)$, and triglyceride $(P=0.006)$ were significantly reduced in rats that received ATC treatment. In contrast, the higher dose of ATC appeared to significantly induce higher levels of immunoglobulins A, G, and M $(P<0.0001)$.

\section{Effects of ATC on antioxidant capacity in the serum and liver}

The ATC significantly increased antioxidase activity and decreased malonaldehyde concentration in the serum and liver (Fig. 3). Compared with the control group, ATC had no effects on total superoxide dismutase activity in the serum or catalase activity $(P>0.05)$. However, ATC supplementation significantly increased the activity of total superoxide dismutase in the liver $(P<0.0001)$ and glutathione peroxidase $(P<0.0001)$, increased the total antioxidant capacity level $(P<0.0001)$, and decreased malonaldehyde content $(P<0.0001)$ in the serum and liver; the most robust effects were seen in the $250-1,250 \mathrm{mg} / \mathrm{kg}$ groups.

\section{Effects of ATC on anatomy map and histopathological changes in rat mastitis model}

As shown in Figs. 4 and 5, normal anatomic formation of mammary tissue in the control and ATC groups was observed. In the control and ATC groups, no pathologic 


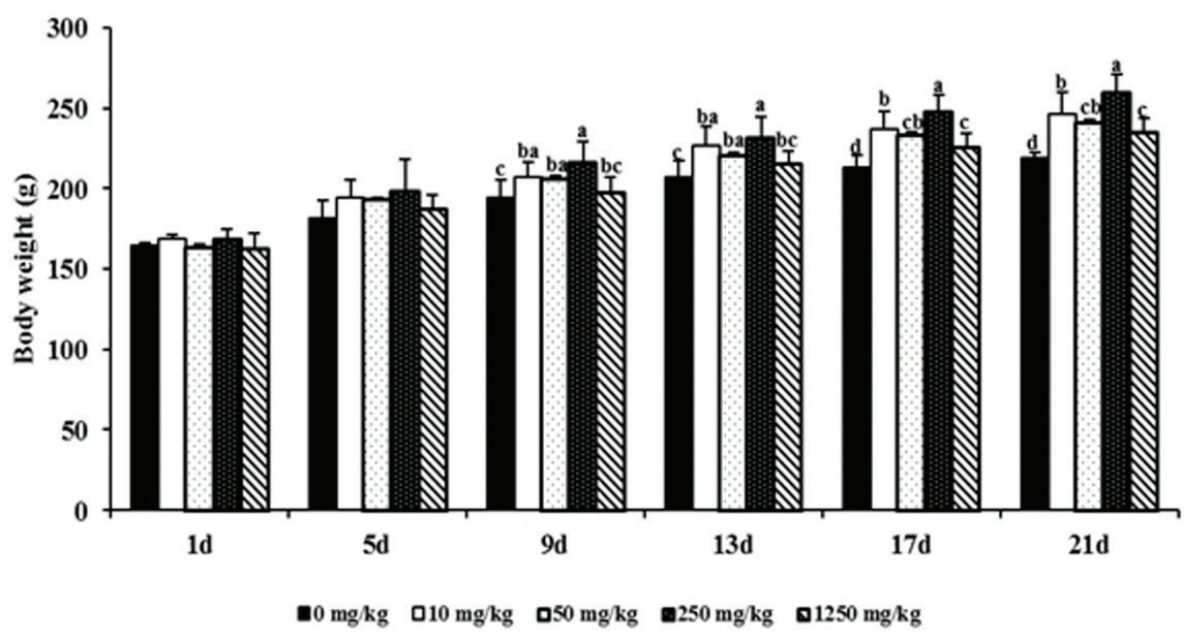

Fig. 1. Effects of Acremonium terricola culture (ATC) on body weight (BW) in SD rats. $0 \mathrm{mg} / \mathrm{kg}=$ gastric perfusion of saline; $10 \mathrm{mg} / \mathrm{kg}=$ gastric perfusion of $10 \mathrm{mg} / \mathrm{kg} \mathrm{BW} \mathrm{ATC;} 50 \mathrm{mg} / \mathrm{kg}=$ gastric perfusion of $50 \mathrm{mg} / \mathrm{kg} \mathrm{BW} \mathrm{ATC;} 250 \mathrm{mg} / \mathrm{kg}=\mathrm{gastric}$ perfusion of $250 \mathrm{mg} / \mathrm{kg} \mathrm{BW}$ ATC; $1,250 \mathrm{mg} / \mathrm{kg}=$ gastric perfusion of $1,250 \mathrm{mg} / \mathrm{kg} \mathrm{BW}$ ATC. Means with different letters within the same row differ significantly $(P<0.05)$. The error bars represent the $\mathrm{SD}(n=8$ rats/group).

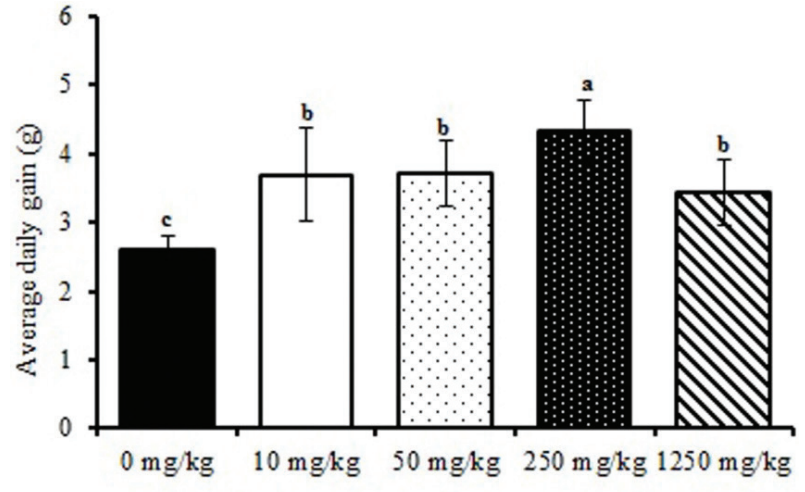

Fig. 2. Effects of ATC on average daily gain in SD rats. $0 \mathrm{mg} /$ $\mathrm{kg}=$ gastric perfusion of saline; $10 \mathrm{mg} / \mathrm{kg}=$ gastric perfusion of $10 \mathrm{mg} / \mathrm{kg} \mathrm{BW} \mathrm{ATC;} 50 \mathrm{mg} / \mathrm{kg}=$ gastric perfusion of $50 \mathrm{mg} / \mathrm{kg}$ BW ATC; $250 \mathrm{mg} / \mathrm{kg}=$ gastric perfusion of $250 \mathrm{mg} / \mathrm{kg} \mathrm{BW} \mathrm{ATC \text {; }}$ $1,250 \mathrm{mg} / \mathrm{kg}=$ gastric perfusion of $1,250 \mathrm{mg} / \mathrm{kg}$ BW ATC. Means with different letters within the same row differ significantly $(P<$ $0.05)$. The error bars represent the $\mathrm{SD}$ ( $n=8$ rats/group).

changes were observed in the mammary glands. However, in the LPS group, we found obvious inflammatory response in mammary glands, such as red and swollen tissue, and the mammary glands were infiltrated with multiple inflammatory cells. In the LPS+ATC group, the LPS-induced pathological changes and inflammatory cell infiltration in the mammary glands were significantly ameliorated compared with the LPS group. The structural integrity of the mammary gland cells was obviously restored.

\section{Effects of ATC on cytokine production}

As shown in Fig. 6, after LPS stimulation, the contents of TNF- $\alpha$, IL-1 $\beta$, and IL- 6 explosively increased. Compared with the LPS group, ATC reduced the production of TNF- $\alpha$, IL-1 $\beta$, and IL- 6 in the LPS+ATC group. No significant changes were seen in the control and ATC groups. The qRT-PCR data were consistent with the results of ELISA experiments.

\section{Effects of ATC on antioxidant function}

We observed that antioxidant functions were significantly lower in the LPS group and increased with higher ATC intake levels, although The total antioxidant capacity (T-AOC). was still lower than in the control group (Fig. 7).

\section{Effects of ATC on the expression of LPS-induced iNOS}

The effect of ATC on the expression of LPS-induced iNOS was studied. Fig. 8 shows the results of iNOS expression in mammary glands. The ATC supplement decreased LPS-induced iNOS expression in the LPS+ATC group compared with the LPS group.

Effects of ATC on the expression of TLR4

The expression of TLR4 was observed in the mammary gland tissue (Fig. 9). After stimulation with LPS, Western blot analysis showed that the expression of TLR4 was markedly higher than in the control group but was downregulated in the LPS+ATC group.

Effects of ATC on the MAPK signaling pathways

As shown in Fig. 10, MAPK signal pathways were activated by LPS, and the phosphorylation levels of ERK and JNK were markedly increased. However, compared with the LPS group, ATC pretreatment significantly inhibited the LPS-induced increase in ERK and JNK phosphorylation in the ATC+LPS group. 
Table 2. Effects of Acremonium terricola culture on serum biochemical parameters in rats

\begin{tabular}{|c|c|c|c|c|c|c|c|}
\hline \multirow[t]{2}{*}{ Item } & \multicolumn{5}{|c|}{ Dose } & \multirow[t]{2}{*}{ SEM } & \multirow[t]{2}{*}{$P$} \\
\hline & $\begin{array}{c}0 \mathrm{mg} / \mathrm{kg} \\
\mathrm{BW}\end{array}$ & $\begin{array}{c}10 \mathrm{mg} / \mathrm{kg} \\
\mathrm{BW}\end{array}$ & $\begin{array}{c}50 \mathrm{mg} / \mathrm{kg} \\
\mathrm{BW}\end{array}$ & $\begin{array}{c}250 \mathrm{mg} / \mathrm{kg} \\
\mathrm{BW}\end{array}$ & $1,250 \mathrm{mg} / \mathrm{kg}$ BW & & \\
\hline$\overline{\mathrm{TP}}(\mathrm{g} / \mathrm{L})$ & 74.75 & 72.50 & 76.75 & 75.25 & 74.00 & 1.18 & 0.16 \\
\hline ALT (IU/L) & $50.63^{a}$ & $39.25^{\mathrm{cb}}$ & $36.25^{\mathrm{cd}}$ & $32.50^{d}$ & $42.75^{b}$ & 1.80 & $<0.0001$ \\
\hline AST (IU/L) & $192.13^{\mathrm{a}}$ & $153.00^{\mathrm{b}}$ & $168.25^{b}$ & $160.00^{\mathrm{b}}$ & $165.25^{\mathrm{b}}$ & 5.71 & 0.0004 \\
\hline $\mathrm{TG}(\mathrm{mmol} / \mathrm{L})$ & $0.95^{\mathrm{a}}$ & $0.95^{\mathrm{a}}$ & $0.82^{b}$ & $0.77^{\mathrm{b}}$ & $0.87^{\text {ba }}$ & 0.04 & 0.006 \\
\hline $\mathrm{CHOL}(\mathrm{mmol} / \mathrm{L})$ & $2.37^{\mathrm{a}}$ & $1.75^{\mathrm{b}}$ & $1.87^{\mathrm{b}}$ & $1.78^{\mathrm{b}}$ & $1.87^{\mathrm{b}}$ & 0.10 & 0.0005 \\
\hline $\mathrm{HDL}(\mathrm{mmol} / \mathrm{L})$ & 0.71 & 0.70 & 0.74 & 0.67 & 0.71 & 0.02 & 0.43 \\
\hline LDL (mmol/L) & $0.30^{\mathrm{a}}$ & $0.20^{\mathrm{b}}$ & $0.23^{b}$ & $0.19^{b}$ & $0.22^{\mathrm{b}}$ & 0.01 & $<0.0001$ \\
\hline SUN (mmol/L) & $7.00^{\mathrm{a}}$ & $6.28^{\mathrm{ba}}$ & $5.73^{\mathrm{bc}}$ & $5.30^{c}$ & $5.48^{c}$ & 0.25 & 0.0002 \\
\hline $\operatorname{AKP}(I U / L)$ & 158.88 & 154.00 & 160.25 & 167.25 & 158.50 & 3.29 & 0.0992 \\
\hline $\lg \mathrm{A}(\mu \mathrm{g} / \mathrm{mL})$ & $28.38^{c}$ & $28.84^{c}$ & $30.91^{\mathrm{b}}$ & $34.77^{\mathrm{b}}$ & $35.88^{a}$ & 0.70 & $<0.0001$ \\
\hline $\lg G(\mu g / m L)$ & $275.47^{d}$ & $285.45^{d}$ & $315.17^{c}$ & $377.79^{a}$ & $363.57^{b}$ & 4.87 & $<0.0001$ \\
\hline $\operatorname{lgM}(\mu \mathrm{g} / \mathrm{mL})$ & $7.5 \mathrm{I}^{\mathrm{d}}$ & $7.75^{\mathrm{cd}}$ & $8.62^{\mathrm{cb}}$ & $10.15^{\mathrm{a}}$ & $9.09^{b}$ & 0.30 & $<0.0001$ \\
\hline
\end{tabular}

${ }^{a-d}$ Within row means with different superscripts are significantly different at $P<0.05$.

TP: total protein; AKP: alkaline phosphatase; SUN: serum urea nitrogen; ALT: alanine transaminase; AST: aspartate transaminase; CHOL: cholesterol; TG: triglyceride; HDL: high-density lipoprotein; LDL: low-density lipoprotein; IgA: immunoglobulin A; IgM: immunoglobulin M; lgG: immunoglobulin G.
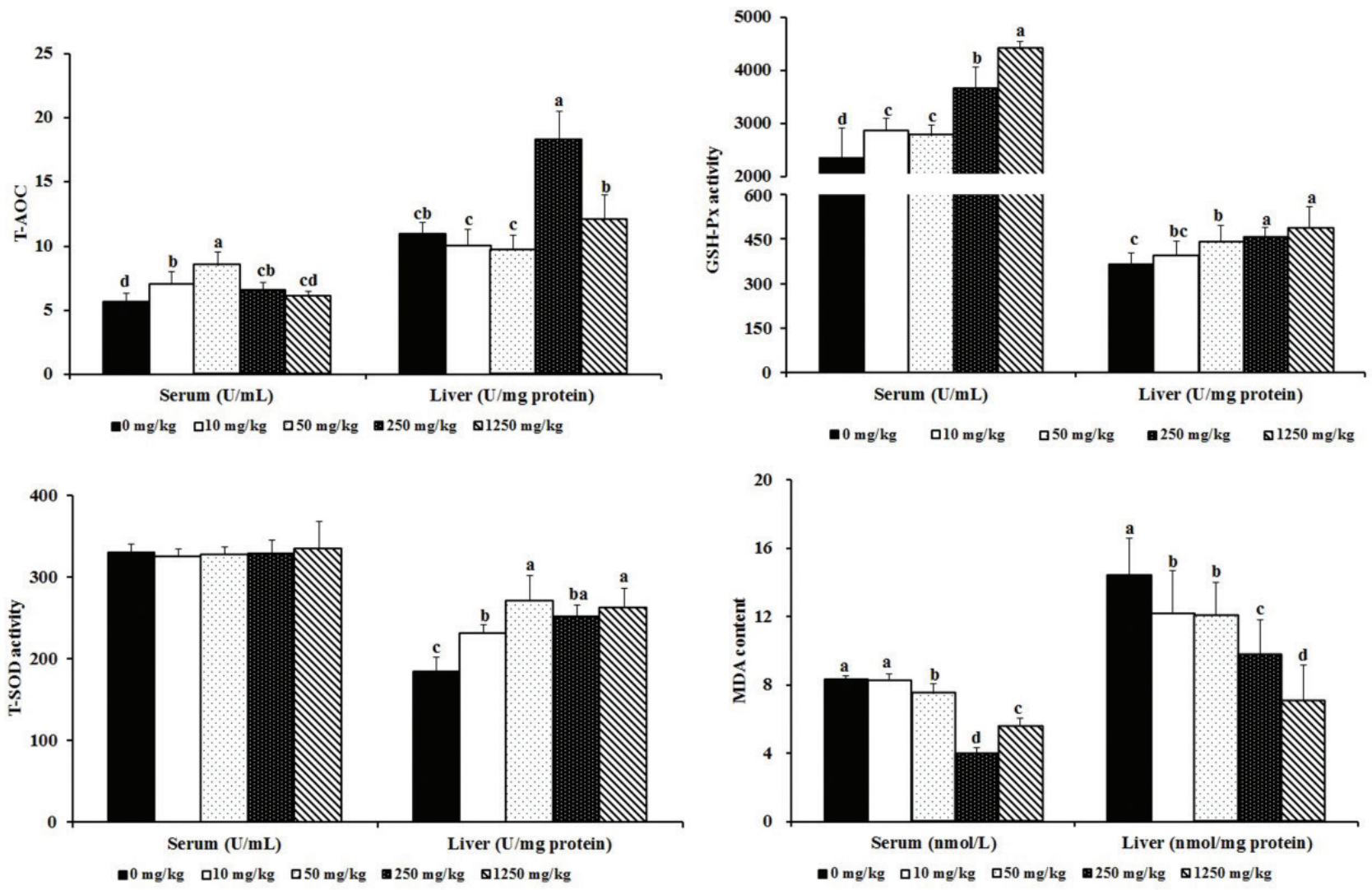

Fig. 3. Effects of ATC on antioxidant functions in SD rats. $0 \mathrm{mg} / \mathrm{kg}=$ gastric perfusion of saline; $10 \mathrm{mg} / \mathrm{kg}=$ gastric perfusion of $10 \mathrm{mg} / \mathrm{kg} \mathrm{BW} \mathrm{ATC;} 50 \mathrm{mg} / \mathrm{kg}=$ gastric perfusion of $50 \mathrm{mg} / \mathrm{kg}$ BW ATC; $250 \mathrm{mg} / \mathrm{kg}=$ gastric perfusion of $250 \mathrm{mg} / \mathrm{kg}$ BW ATC; $1,250 \mathrm{mg} / \mathrm{kg}=$ gastric perfusion of $1,250 \mathrm{mg} / \mathrm{kg}$ BW ATC. Means with different letters within the same row differ significantly $(P<0.05)$. The error bars represent the $\mathrm{SD}(n=8$ rats/group). 


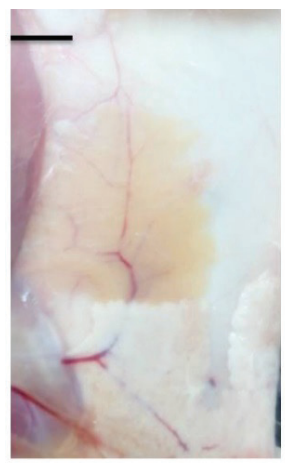

CON

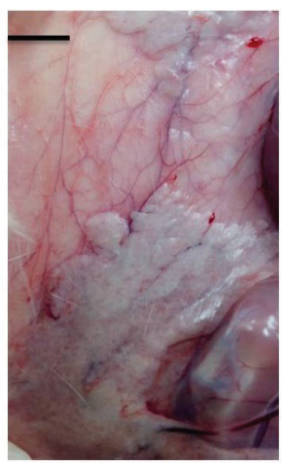

LPS

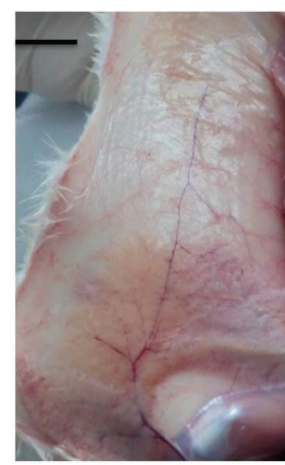

LPS+ATC

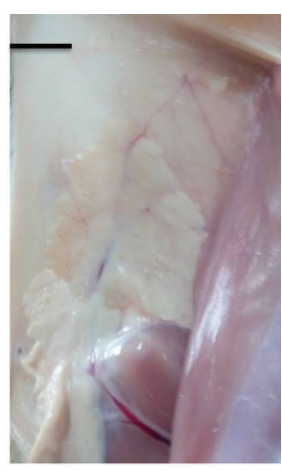

ATC

Fig. 4. Anatomy maps of mammary glands in rats. Twenty-four hours after the infusion of LPS, anatomy maps of mammary glands in rats were observed. CON = control group; LPS = LPS group; LPS + ATC = LPS + ATC group $(250 \mathrm{mg} / \mathrm{kg}$ BW by gavage $) ;$ ATC $=$ ATC group $(250 \mathrm{mg} / \mathrm{kg}$ BW by gavage $)$. Scale bars, $1 \mathrm{~cm}$.

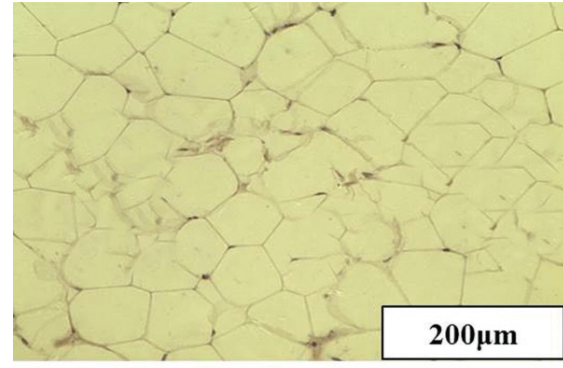

CON

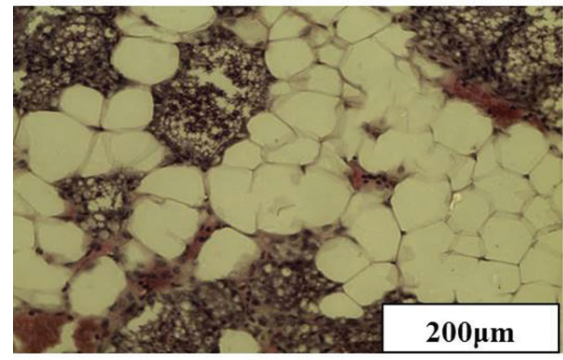

LPS+ATC

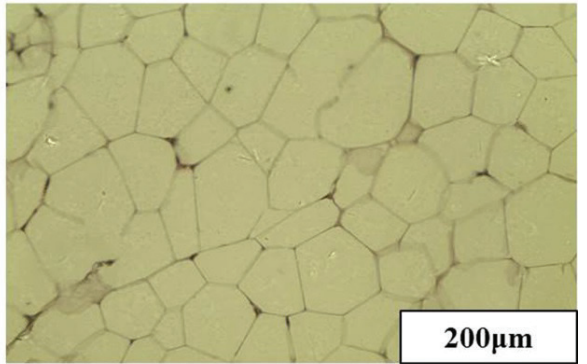

ATC

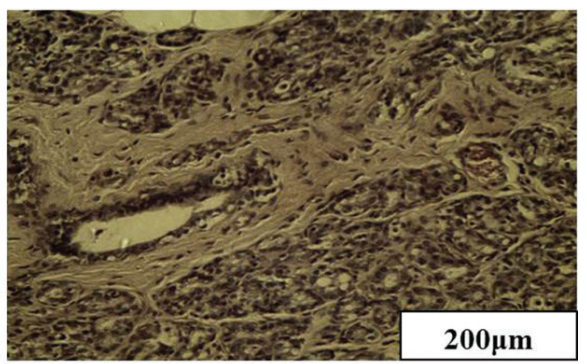

LPS

Fig. 5. Effects of ATC on histopathological changes in LPS-induced mammary glands. Twenty-four hours after the infusion of LPS, the histopathology of mammary glands was observed by H\&E staining. CON = control group; LPS = LPS group; LPS + ATC $=$ LPS + ATC group ( $250 \mathrm{mg} / \mathrm{kg} \mathrm{BW}$ by gavage $) ;$ ATC = ATC group $(250 \mathrm{mg} / \mathrm{kg}$ BW by gavage $)$.

\section{Discussion}

For the first time, we demonstrated that ATC improves the productivity and health of rats. The reason ATC supplementation can enhance growth performance and health is mainly due to the presence of specific compounds, such as cordycepic acid, Cordyceps polysaccharide, and cordycepin. ATC and Cordyceps substances containing the same active ingredients are known as Cordyceps feed additive due to similar biological function. Furthermore, many studies have reported that Cordyceps substances and active ingredients have the ability to improve growth performance and antioxidant function. The improvement of growth performance in broiler chicks (18) and laying hens (19) after feeding with fermentation products and the by-product of Cordyceps militaris, and the enhancement of $\mathrm{BW}$ and feed conversion rate of white shrimp (20) after supplementing with Cordyceps polysaccharides suggest that Cordyceps substances and active ingredients are effective in applications for animal husbandry. Additionally, our previous study showed that ATC supplementations accelerated the BW gain of calves, increased the BW and feed efficiency, and improved antioxidant and immune functions (7), which are results similar to those of the current study. The mechanism for the growth performance improvement of rats may be attributed to ATC increasing 

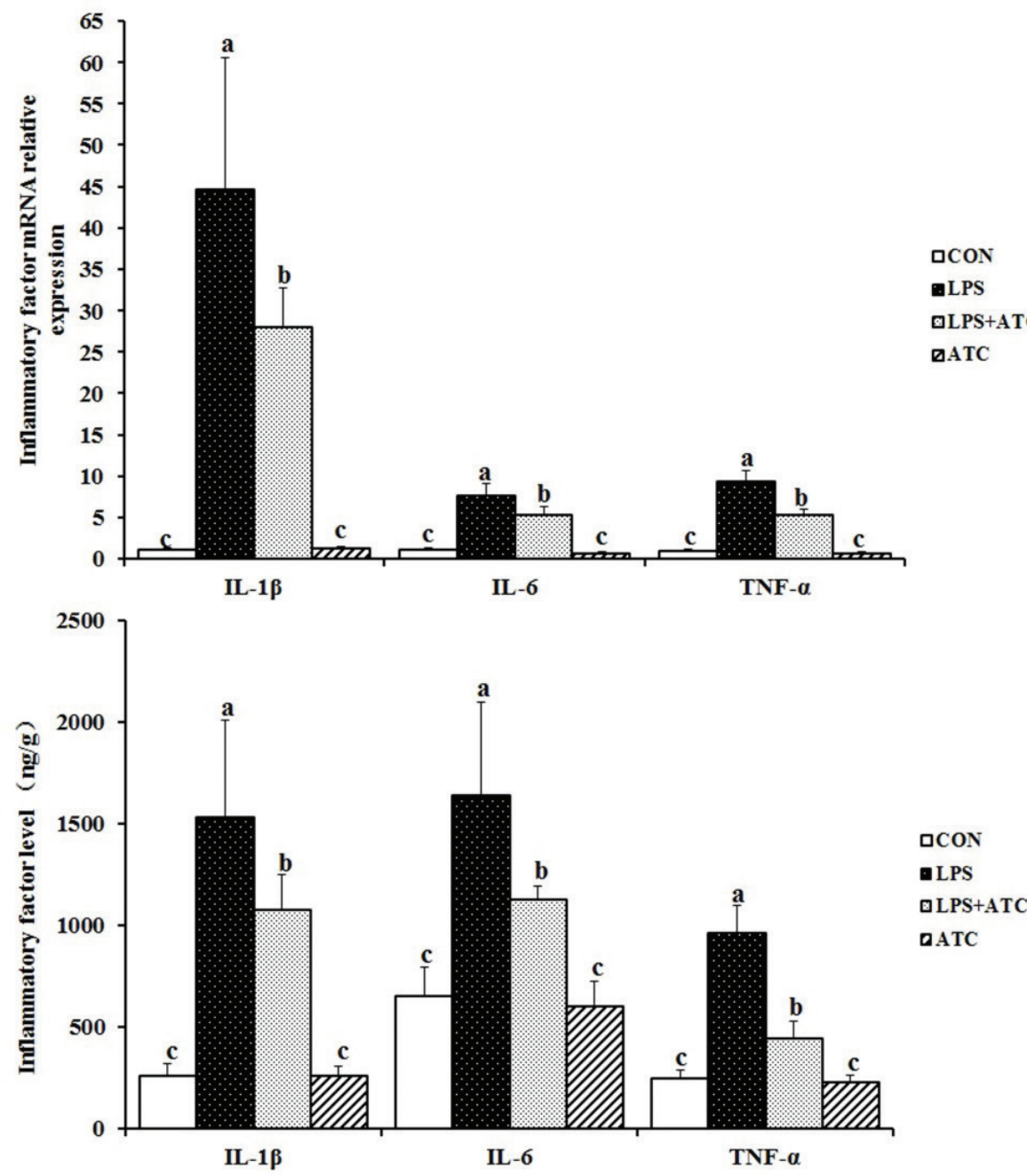

Fig. 6. Effects of ATC on cytokine production in LPS-induced mammary glands. RT-PCR and ELISA were used to measure the relative mRNA expression and production of cytokines in the mammary gland homogenates. CON = control group; LPS $=$ LPS group; LPS + ATC = LPS + ATC group $(250 \mathrm{mg} / \mathrm{kg} \mathrm{BW}$ by gavage $) ;$ ATC $=$ ATC group $(250 \mathrm{mg} / \mathrm{kg}$ BW by gavage $)$. Means with different letters within the same row differ significantly $(P<0.05)$. The error bars represent the SD $(n=10$ rats/group).

the feed conversion ratio (20). The $\mathrm{BW}$ gain of rats might also be related to the antibacterial action of functional ingredients of ATC. Previous studies have demonstrated that cordycepin and Cordyceps polysaccharides have inhibitory effects on bacteria $(21,22)$. Studies with broiler chicks have demonstrated that extracts of mycelia from Cordyceps sinensis inhibited pathogenic bacterial growth and increased the population of Lactobacillus spp. in the small intestine, which, in turn, improved BW gain (23). Therefore, the antibacterial action and probiotic function of the active ingredient in ATC are key factors in the improvement of growth performance. The objective of this trial was to determine the optimal dose for subsequent testing, so intestinal flora was not detected. Therefore, this topic still requires further study to illuminate the influence of ATC on intestinal microbial population and digestive metabolism.
Serum biochemical indicators comprehensively reflect body status and are the most sensitive and direct indicators mirroring the health condition of rats. The serum total protein, high-density lipoprotein, and alkaline phosphatase levels were not influenced by ATC addition. ALT and AST levels are important parameters, which indicate the status of hepatic cells. Previous studies have demonstrated that $C$. sinensis mycelial powder (24) and extract of C. militaris (25) are able to improve antioxidant function in rats, inhibit the secretion of pro-inflammatory factors in rats, and reduce the activities of AST and ALT. In the current study, decreases in the AST and ALT contents suggest that ATC may have protective effects on hepatic cells, which may be related to the antioxidant and antiinflammatory effects of the active ingredients in ATC.

High levels of blood triglyceride, cholesterol, and low-density lipoprotein are responsible for cardiovascular 
GSH-Px
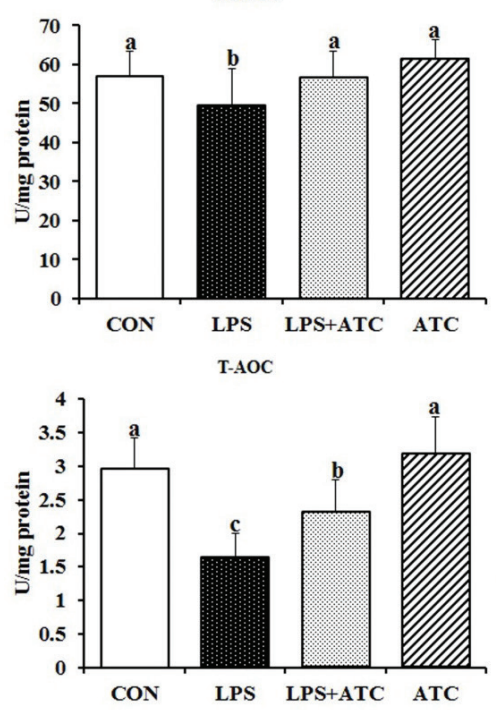

T-SOD
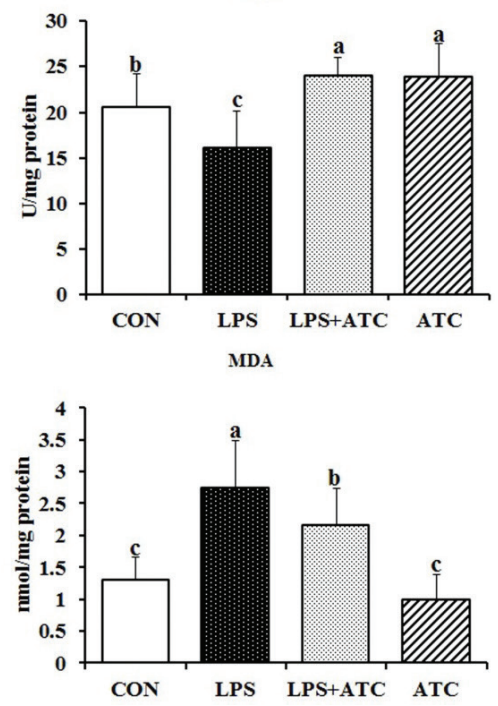

Fig. 7. Effects of ATC on antioxidant functions in LPS-induced mammary gland. CON = control group; LPS = LPS group; LPS + ATC $=$ LPS + ATC group $(250 \mathrm{mg} / \mathrm{kg}$ BW by gavage $) ;$ ATC $=$ ATC group $(250 \mathrm{mg} / \mathrm{kg} \mathrm{BW}$ by gavage $)$. Means with different letters within the same row differ significantly $(P<0.05)$. The error bars represent the $\mathrm{SD}(n=10$ rats/group).

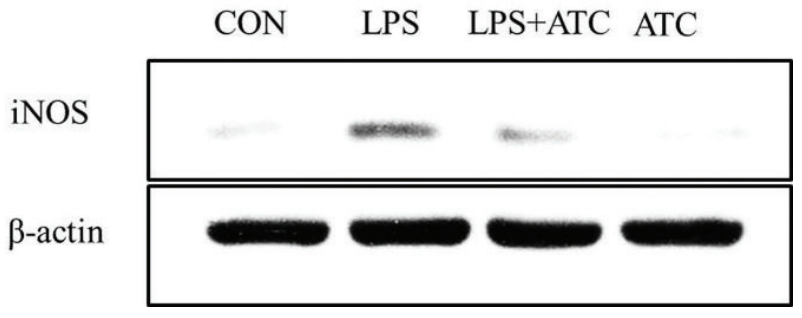

Fig. 8. Effects of ATC on iNOS expression in LPS-induced mammary gland. Mammary tissue was then prepared, and Western blots were performed using an antibody specific for murine iNOS. CON = control group; LPS = LPS group; LPS $+\mathrm{ATC}=\mathrm{LPS}+\mathrm{ATC}$ group $(250 \mathrm{mg} / \mathrm{kg} \mathrm{BW}$ by gavage $) ;$ ATC $=\operatorname{ATC}$ group $(250 \mathrm{mg} / \mathrm{kg} \mathrm{BW}$ by gavage $) ;(n=10 \mathrm{rats} /$ group $)$.

diseases (26). In the current study, a very significant decrease was observed in the levels of low-density lipoprotein, triglyceride, and cholesterol, strengthening the lipid-lowering activity and illustrating the cardio-protective effects of ATC. Kiho et al. suggested that the levels of blood triglyceride and cholesterol in normal and diabetic rats decreased in the treatment group at 3 or $6 \mathrm{~h}$ after the addition of Cordyceps polysaccharide (27). Park et al. also observed that the addition of $C$. militaris to diabetic rats resulted in apparent decrease in the levels of triglyceride, total cholesterol, and low-density lipoprotein-cholesterol (28). Based on our study, increases in functional components (Cordyceps polysaccharide, cordycepic acid, and cordycepin) are vital in preventing cardiovascular and cerebrovascular diseases, but the reason for this is still unclear. Therefore, further research is needed to explore the underlying mechanism of disease prevention. SUN is one
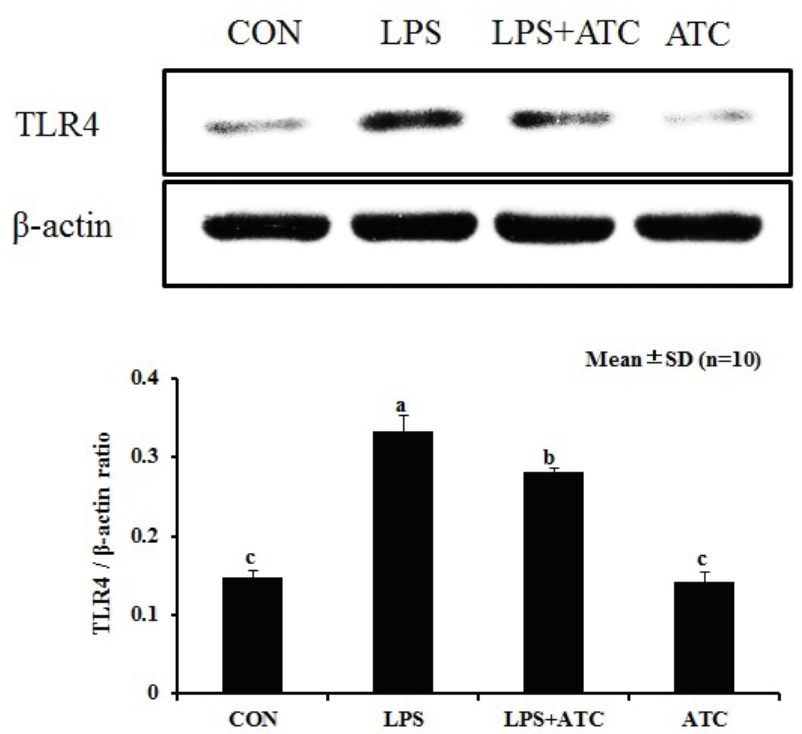

Fig. 9. Effects of ATC on the expression of TLR4 in LPS-induced mammary glands. MAPK protein samples were analyzed by Western blot with specific antibodies. $\beta$-Actin was used as a control. Means with different letters within the same row differ significantly $(P<0.05)$. The error bars represent the SD. CON = control group; LPS = LPS group; LPS + $\mathrm{ATC}=\mathrm{LPS}+\mathrm{ATC}$ group $(250 \mathrm{mg} / \mathrm{kg}$ BW by gavage $) ;$ ATC = ATC group ( $250 \mathrm{mg} / \mathrm{kg} \mathrm{BW}$ by gavage).

of the important indicators, which reflects renal function. An increasing level of urea nitrogen in the serum suggests the kidneys may be damaged. Research shows that a Chinese herb can reduce nephrotoxicity and decrease SUN content (29). $\mathrm{Li}$ et al. found that addition of C. sinensis 

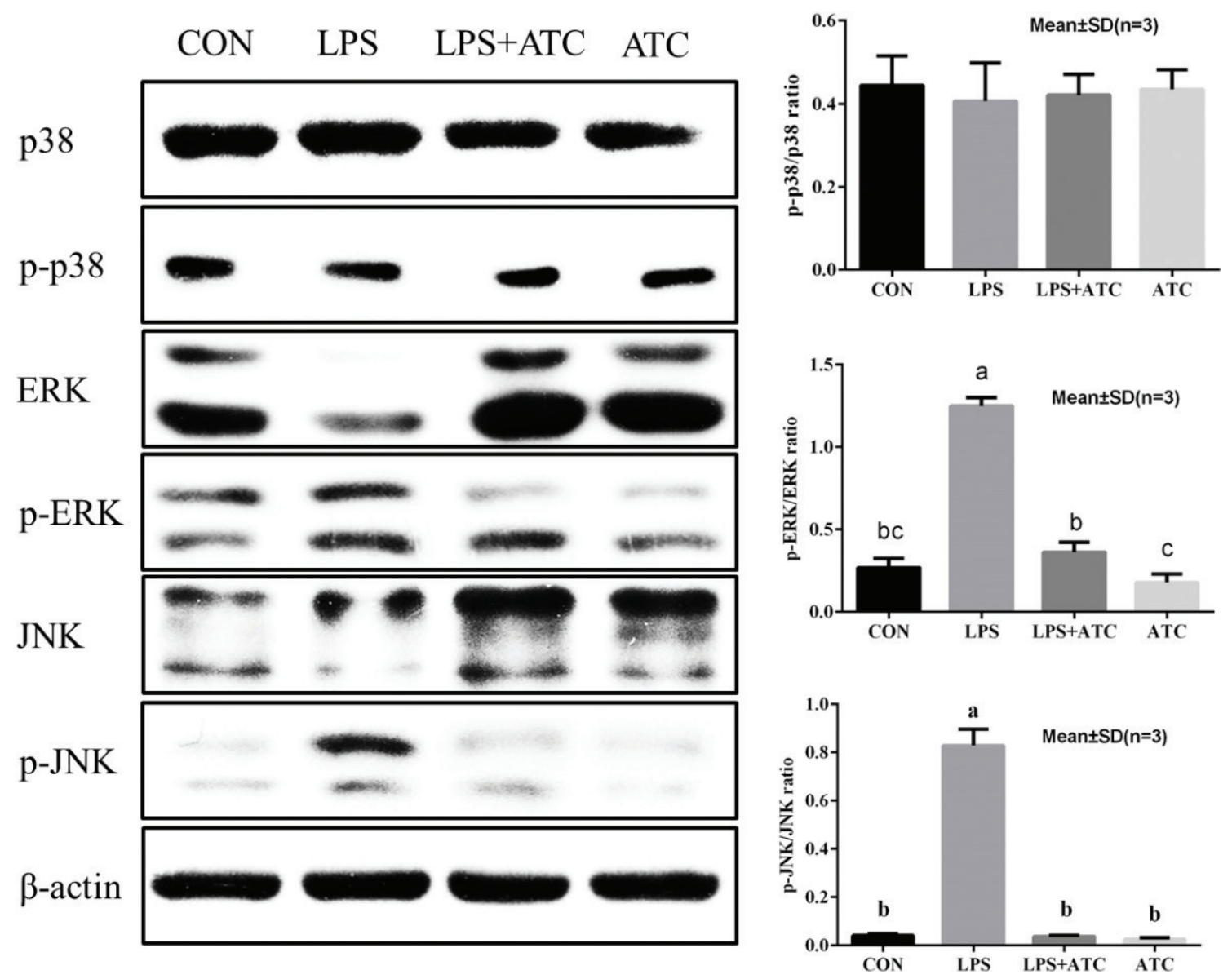

Fig. 10. Effects of ATC on the expression of MAPKs in LPS-induced mammary glands. MAPK protein samples were analyzed by Western blot with specific antibodies. $\beta$-Actin was used as a control. Means with different letters within the same row differ significantly $(P<0.05)$. The error bars represent the SD. CON = control group; LPS = LPS group; LPS + ATC = LPS + ATC group ( $250 \mathrm{mg} / \mathrm{kg} \mathrm{BW}$ by gavage); ATC = ATC group ( $250 \mathrm{mg} / \mathrm{kg} \mathrm{BW}$ by gavage).

markedly decreased the total cholesterol content and reduced the levels of ALT and urea nitrogen in the serum of patients, which is consistent with our results (30). Immunoglobulins are proteins that bind to foreign agents, such as bacteria and viruses, and help to eliminate them from the body, thereby leading to complement activation and neutralization of toxins. Our results indicated that administration of ATC greatly increases the contents of immunoglobulin A, G, and M. There is a great deal of research that shows that the active ingredients and extracts of Cordyceps improved the concentrations of immunoglobulins and enhanced the humoral immune function in rats (31-33), agreeing with our findings.

Total antioxidant capacity is a single measurement that describes the dynamic equilibrium between prooxidants and antioxidants. Free-radical-induced lipid peroxidation is an important consequence of oxidative stress and has been associated with a number of diseases. Malonaldehyde is often used as an indicator of oxidative stress and is also a product of lipid peroxidation. Therefore, measuring these indices may help us understand the antioxidant function of rats. Active ingredients of cultured C. sinensis exert potent antioxidant and anti-lipid peroxidation functions and can be effective in scavenging various types of oxygen-free radicals and their products $(20,34,35)$. Research has demonstrated that cordycepin may be a promising candidate for the prevention of alcohol-induced hepatotoxicity (36), and C. sinensis shows great potential for preventing hepatinica $(24,37,38)$. Using both serum and tissue research in rats, Liu et al. concluded that C. militaris polysaccharides can improve the antioxidant capacity of the liver and reduce the malonaldehyde content in the serum, similar to our results (32). Additionally, ATC demonstrated its strong antioxidant function by significantly improving antioxidase activity and decreasing SCC in calves and dairy cows $(6,7)$. These positive results, already reported in a variety of studies $(24,28,39)$, only demonstrated the function of the active ingredient 
in Cordyceps, whereas the research on its antioxidative mechanisms is lacking. This is why further study is required to determine its mode of action. After analyzing our results, we found many favorable outcomes regarding growth performance and serum biochemical indicators in the $250 \mathrm{mg} / \mathrm{kg}$ group. Therefore, subsequent research in Experiment 2 was conducted with this dosage.

Mastitis is a common multiple disease in dairy cows. As the main cause of considerable economic losses, prevention and treatment of mastitis is critical for the dairy industry (2). However, because there are many disadvantages of experiments using cows, such as difficulty and expense, over the last few years, the mastitis model has been used to prevent inflammation extensively (3). Previous studies have demonstrated that ATC significantly decreased SCC in milk and increased milk production of dairy cows (6). Therefore, we think that ATC may have very good protective effects against mastitis. In the current study, E. coli LPS caused redness and swelling of nipples, and the LPS-induced pathological changes and the infiltration of inflammatory cells in the mammary glands were significantly ameliorated by administration with ATC. This astonishing phenomenon confirmed that ATC has potent anti-inflammatory activity.

To understand further anti-inflammatory mechanisms of ATC, the rat was chosen as a model for studying antioxidant levels, pro-inflammatory factor regulation, and signal transduction pathways. ATC possesses important anti-inflammatory and immune functions due to the presence of specific compounds. A. terricola was isolated from C. gunnii. The active components (cordycepin, ergosterol, Cordyceps polysaccharide, and cordycepic acid) of ATC are similar to those of natural $C$. gunnii. The role of the active ingredients of Cordyceps in the regulation of cytokines and in antioxidant function has been demonstrated by many experiments $(32,35,39)$. Therefore, based on previous research results, we assumed that Cordyceps polysaccharide in ATC is possibly involved in the antioxidant function of ATC in mammary glands. Research has demonstrated that $C$. militaris polysaccharides can enhance antioxidation ability in immunosuppressed rats by increasing antioxidant enzyme activities and decreasing advanced lipoxidation end product contents in vivo $(35,40)$. Some of the many animals in which Cordyceps polysaccharide and ATC have been found to strengthen antioxidant functions include calves (7), cows (6), rats (35), and aquatic animals (20). It is well known that inflammatory injury can accompany oxidative stress (40). Therefore, that Cordyceps polysaccharides possess a double effect of antioxidation, and anti-inflammation is critical to ATC-enhanced immunity.

Studies have shown that during pathogen infection, pro-inflammatory cytokines play an important role in the inflammatory response in mastitis (41). A reduction in the levels of pro-inflammatory cytokines indicates that ATC exerts a protective effect on organs under excessively inflammatory reactions (42). In the current study, we measured the levels of pro-inflammatory cytokines using RT-PCR and ELISA methods. Both RT-PCR and ELISA showed that the levels of three pro-inflammatory cytokines in the LPS group were significantly higher than those in the control group but significantly lower than in the LPS+ATC group. Therefore, ATC exerts an antiinflammatory effect by inhibiting the release of TNF- $\alpha$, IL-1 $\beta$, and IL-6. Similarly, addition of ATC possibly changes the dynamics of infiltration of other immune cells into the inflamed area, mainly by reducing the secretion of pro-inflammatory cytokines. In addition, we think that the anti-inflammatory effect of ATC is dependent on cordycepin. One study found that cordycepin showed significant anticancer, anti-inflammatory, pharmacological, and immune stimulation effects (8). Moreover, after LPS stimulation, cordycepin inhibited the expression of nitric oxide and showed no cytotoxicity, which is similar to the results of this experiment (8). It has been reported in other contributions that iNOS is usually not expressed in animal tissues, but LPS stimulation causes upregulation of iNOS expression in mammary glands. In the current study, expression of iNOS may be closely related to the anti-inflammatory effect of ATC. We believe, based on the results of the current experiment, that ATC exerts anti-inflammatory function by downregulation of pro-inflammatory mediators. This downregulation may be attributed to the inhibition of the signal transduction pathways of TNF- $\alpha$, IL-6, IL-1 $\beta$, and iNOS expression. As a vital receptor for LPS recognition (43), TLR4 is able to activate the downstream MAPK signaling pathway (44). The MAPK signaling pathway involves ERK, JNK, and p38 kinases, and it plays an important role in the production of inflammatory factors, promoting the expression of pro-inflammatory cytokines (45). Our experimental results confirmed that ATC pretreatment inhibited LPS-induced TLR4 recognition and phosphorylation of downstream ERK and JNK, thereby inhibiting the expression of TNF- $\alpha$, IL-6, IL-1 $\beta$, and iNOS. In conclusion, our results clearly demonstrate that ATC exerts an anti-inflammatory effect by modulating the MAPK signal transduction pathway.

\section{Conclusion}

Our results demonstrate that ATC pretreatment plays a role in anti-inflammatory action by interfering with TLR4 expression, which subsequently inhibits the downstream MAPK signaling pathways and the release of the pro-inflammatory cytokines TNF- $\alpha$, IL- $1 \beta$, and IL-6. Our findings provide the rationale and the mechanism for the 
prevention of bovine mastitis by ATC and suggest that ATC is an effective feed additive for the prevention and treatment of E. coli-induced mastitis.

\section{Authors' contributions}

Y.L. and X.J. contributed equally to this work, and they are both co-first authors. Y.L. and X.J. participated in the design of this study and performed most of the experiments. H.J.X. performed the Western blot and the real-time PCR experiments. J.Y.L., G.N.Z., X.J.D., and X.X.L. performed many assistants during all of the experiments. Y.L. performed the statistical analysis and drafted the main manuscript. Y.G.Z. supervised the work. Y.G.Z. revised the final version of the manuscript. All authors have read and approved the final version of the manuscript.

\section{Acknowledgments}

This study was financially supported by the China Agriculture Research System (CARS-36), the China Postdoctoral Science Foundation for the 65th batch (2019M651252), the Postdoctoral Foundation in Heilongjiang Province (LBH-Z17035), Young Talents 'Project of Northeast Agricultural University' (18QC35), and the Natural Science Foundation of China (NSFC) (31802100). The authors also thank Hefei Micro Biological Engineering Co., Ltd. (Heifei, China) for donating the A. terricola culture used in this study.

\section{Conflict of interest and funding}

The authors have not received any funding or benefits from industry or elsewhere to conduct this study.

\section{References}

1. Bradley A. Bovine mastitis: an evolving disease. Vet J 2002; 164(2): 116-28. doi: 10.1053/tvj1.2002.0724

2. Halasa T, Huijps K, Østerås O, Hogeveen H. Economic effects of bovine mastitis and mastitis management: a review. Vet Quart 2007; 29(1): 18-31. doi: 10.1080/01652176.2007.9695224

3. Song X, Zhang W, Wang T, Jiang H, Zhang Z, Fu Y, et al. Geniposide plays an anti-inflammatory role via regulating TLR4 and downstream signaling pathways in lipopolysaccharide-induced mastitis in mice. Inflammation 2014; 37(5): 1588-98. doi: 10.1007/s10753-014-9885-2

4. Guo M, Zhang N, Li D, Liang D, Liu Z, Li F, et al. Baicalin plays an anti-inflammatory role through reducing nuclear factor- $\mathrm{kB}$ and $\mathrm{p} 38$ phosphorylation in S. aureus-induced mastitis. Int Immunopharmacol 2013; 16(2): 125-30. doi: 10.1016/j. intimp.2013.03.006

5. Wang ZM, Peng X, Lee KLD, Tang JCO, Cheung PCK, Wu JY. Structural characterisation and immunomodulatory property of an acidic polysaccharide from mycelial culture of Cordyceps sinensis fungus Cs-HK1. J Dairy Sci 2011; 125: 637-43. doi: 10.1016/j.foodchem.2010.09.052

6. Li Y, Sun YK, Li X, Zhang GN, Xin HS, Xu HJ, et al. Effects of Acremonium terricola culture on performance, milk composition, rumen fermentation and immune functions in dairy cows. Anim Feed Sci Tech 2018; 240: 40-51. doi: 10.1016/j. anifeedsci.2018.03.015

7. Li Y, Wang YZ, Ding X, Zhang YG, Xue SC, Lin C, et al. Effects of Acremonium terricola culture on growth performance, antioxidant status and immune functions in weaned calves. Livestock Sci 2016; 193: 66-70. doi: 10.1016/j.livsci.2016.09.009

8. Jinwoo J, Jin CY, Giyoung K, Jaedong L, Cheol P, Gundo $\mathrm{K}$, et al. Anti-inflammatory effects of cordycepin via suppression of inflammatory mediators in BV2 microglial cells. Int Immunopharmacol 2010; 10(12): 1580-6. doi: 10.1016/j. intimp.2010.09.011

9. Notebaert S, Meyer E. Mouse models to study the pathogenesis and control of bovine mastitis. A review. Vet Quart 2006; 28(1): 2-13. doi: 10.1080/01652176.2006.9695201

10. Chandler RL. Experimental bacterial mastitis in the mouse. J Med Microbiol 1970; 3(2): 273-82. doi: 10.1099/00222615-3-2-273

11. Breyne K, Vliegher SD, Visscher AD, Piepers S, Meyer E. Technical note: a pilot study using a mouse mastitis model to study differences between bovine associated coagulase-negative staphylococci. J Dairy Sci 2015; 98(2): 1090-100. doi: 10.3168/ jds.2014-8699

12. Tsukamoto H, Takeuchi S, Kubota K, Kobayashi Y, Kozakai S, Ukai I, et al. Lipopolysaccharide (LPS)-binding protein stimulates CD14-dependent toll-like receptor 4 internalization and LPS-induced TBK1-IKK $\epsilon-$ IRF3 axis activation. J Biol Chem 2018; 293: 10186-201. doi: 10.1074/jbc.M117.796631

13. Fan MZ, Huang B, Li CR, Li ZZ. A new record species of the genus Acremonium from China. Mycosystema 1999; 18: 449.

14. Zhang GL, Jiang L, Yan Q, Liu RH, Zhang L. Anti-tumor effect of matrine combined with cisplatin on rat models of cervical cancer. Asian Pac J Trop Med 2015; 8(12): 1055-9. doi: 10.1016/j.apjtm.2015.11.005

15. Chang CY, Lue MY, Pan TM. Determination of adenosine, cordycepin and ergosterol contents in cultivated Antrodia camphorata by HPLC method. J Food Drug Anal 2005; 13(4): 338-42. doi: 10.38212/2224-6614.2569

16. AOAC, 2000. Official Methods of Analysis, 17th ed. Association of Official Analytical Chemist, Arlington, VA, USA.

17. Dou XJ, Gao N, Lan J, Han JL, Yang Y, Shan AS. TLR2/EGFR are two sensors for $\mathrm{pBD} 3$ and $\mathrm{pEP} 2 \mathrm{C}$ induction by sodium butyrate independent of HDAC inhibition. J Agric Food Chem 2020; 68: 512-522. doi: 10.1021/acs.jafc.9b06569

18. Wang JG. Effects of fermentation products of on growth performance and bone mineralization of broiler chicks. J Appl Anim Res 2015; 43(2): 236-41. doi: 10.1080/09712119.2014.928630

19. Wang CL, Chiang CJ, Chao YP, Yu B, Lee TT. Effect of Cordyceps militaris waster medium on production performance, egg traits and egg yolk cholesterol of laying hens. J Poultry Sci 2015; 52(3): 188-96. doi: 10.2141/jpsa.0140191

20. Deng B, Wang ZP, Tao WJ, Li WF, Wang C, Wang MQ, et al. Effects of polysaccharides from mycelia of Cordyceps sinensis on growth performance, immunity and antioxidant indicators of the white shrimp Litopenaeus vannamei. Aquacult Nutr 2015; 21(2): 173-9. doi: 10.1111/anu.12147

21. Ahn YJ, Park SJ, Lee SG, Shin SC, Choi DH. Cordycepin: selective growth inhibitor derived from liquid culture of Cordyceps militaris against Clostridium spp. J Agric Food Chem 2000; 48(7): 2744-8. doi: 10.1021/jf990862n

22. Xiao JH, Liang ZQ, Liu AY, Chen DX, Xiao Y, Liu JW, et al. Immunosuppressive activity of polysaccharides from Cordyceps gunnii mycelia in mice in vivo/vitro. J Food Agric Environ 2004; 2(3-4): 69-73. 
23. Koh JH, Suh HJ, Ahn TS. Hot-water extract from mycelia of Cordyceps sinensis as a substitute for antibiotic growth promoters. Biotechnol Lett 2003; 25(7): 585-90. doi: 10.1023/A: 1022893000418

24. Ko WS, Hsu SL, Chyau CC, Chen KC, Peng RY. Compound Cordyceps TCM-700C exhibits potent hepatoprotective capability in animal model. Fitoterapia 2010; 81(1): 1-7. doi: 10.1016/j. fitote.2009.06.018

25. Haneul C, Yanghee J, Minjoo K, Minjeong S, Kang BW, Yongkee J, et al. Cordyceps militaris alleviates non-alcoholic fatty liver disease in ob/ob mice. Nutr Res Pract 2014; 8(2): 172-6. doi: 10.4162/nrp.2014.8.2.172

26. Ademuyiwa O, Ugbaja RN, Idumebor F, Adebawo O. Plasma lipid profiles and risk of cardiovascular disease in occupational lead exposure in Abeokuta, Nigeria. Lipids Health Dis 2005; 4(1): 19. doi: 10.1186/1476-511X-4-19

27. Kiho T, Yamane A, Hui J, Usui S, Ukai S. Polysaccharides in fungi. XXXVI. Hypoglycemic activity of a polysaccharide (CS-F30) from the cultural mycelium of Cordyceps sinensis and its effect on glucose metabolism in mouse liver. Biol Pharmaceut Bull 1996; 19(2): 294-6. doi: 10.1248/bpb.19.294

28. Park JH, Park NS, Sang ML, Park E. Effect of Dongchunghacho rice on blood glucose level, lipid profile, and antioxidant metabolism in streptozotocin-induced diabetic rats. Food Sci Biotechnol 2011; 20(4): 933-40. doi: 10.1007/s10068-011-0129-z

29. Kalkan Y, Kapakin KA, Kara A, Atabay T, Karadeniz A, Simsek N, et al. Protective effect of Panax ginseng against serum biochemical changes and apoptosis in kidney of rats treated with gentamicin sulphate. J Mol Histol 2012; 43(5): 603-13. doi: 10.1007/s10735-012-9412-4

30. Li Y, Xue WJ, Tian PX, Ding XM, Yan H, Pan XM, et al. Clinical application of Cordyceps sinensis on immunosuppressive therapy in renal transplantation. Transplant P 2009; 41(5): 1565-9. doi: 10.1016/j.transproceed.2009.02.085

31. Chae SW, Mitsunaga F, Jung SJ, Ha KC, Sin HS, Jang SH, et al. Nutrigenomic study on immunomodulatory function of mycelium extract (Paecilomyces hepiali) in mitomycin C-treated mice. Food Nutr Sci 2014; 5(22): 2217-24. doi: 10.4236/ fns. 2014.522235

32. Liu JY, Feng CP, Li X, Chang MC, Meng JL, Xu LJ. Immunomodulatory and antioxidative activity of Cordyceps militaris polysaccharides in mice. Int J Biol Macromol 2016; 86: 594-8. doi: 10.1016/j.ijbiomac.2016.02.009

33. Wu Y, Sun H, Qin F, Pan Y, Sun C. Effect of various extracts and a polysaccharide from the edible mycelia of Cordyceps sinensis on cellular and humoral immune response against ovalbumin in mice. Phytother Res 2006; 20(8): 646-52. doi: 10.1002/ ptr.1921

34. Yamaguchi Y, Kagota S, Nakamura K, Shinozuka K, Kunitomo M. Antioxidant activity of the extracts from fruiting bodies of cultured Cordyceps sinensis. Phytother Res 2015; 14(8): 647-9. doi: 10.1002/1099-1573(200012)14:8\%3C647::AIDPTR670\%3E3.0.CO;2-W

35. Wang M, Meng XY, Yang RL, Qin T, Wang XY, Zhang KY, et al. Cordyceps militaris polysaccharides can enhance the immunity and antioxidation activity in immunosuppressed mice. Carbohyd Polym 2012; 89(2): 461-6. doi: 10.1016/j. carbpol.2012.03.029

36. Cha JY, Ahn HY, Cho YS, Je JY. Protective effect of cordycepin-enriched Cordyceps militaris on alcoholic hepatotoxicity in Sprague-Dawley rats. Food Chem Toxicol 2013; 60(10): 52-7. doi: 10.1016/j.fct.2013.07.033

37. Wu R, Gao JP, Wang HL, Gao Y, Wu Q, Cui XH. Effects of fermented Cordyceps sinensis on oxidative stress in doxorubicin treated rats. Pharmacogn Mag 2015; 11(44): 724-31. doi: 10.4103/0973-1296.165562

38. Yuan P, Qian C, Tao Y, Tao Y, Xiong L, Liu C. Cultured mycelium Cordyceps sinensis protects liver sinusoidal endothelial cells in acute liver injured mice. Mol Biol Rep 2014; 41(3): 1815-27. doi: 10.1007/s11033-014-3031-y

39. Chiu CH, Chyau CC, Chen CC, Lin CH, Cheng CH, Mong MC. Polysaccharide extract of Cordyceps sobolifera attenuates renal injury in endotoxemic rats. Food Chem Toxicol Int J 2014; 69: 281-8. doi: 10.1016/j.fct.2014.04.009

40. Zhang J, Yu Y, Zhang Z, Ding Y, Dai X, Li Y. Effect of polysaccharide from cultured Cordyceps sinensis on immune function and anti-oxidation activity of mice exposed to ${ }^{60} \mathrm{Co}$. Int Immunopharmacol 2011; 11(12): 2251-7. doi: 10.1016/j. intimp.2011.09.019

41. Rainard P, Riollet C. Innate immunity of the bovine mammary gland. Vet Res 2015; 37(3): 369-400. doi: 10.1051/vetres:2006007

42. Moore EE, Presnell S, Garrigues U, Guilbot A, Leguern E, Smith D, et al. Expression of IL-17B in neurons and evaluation of its possible role in the chromosome 5q-linked form of Charcot-Marie-Tooth disease. Neuromuscular Disord 2002; 12(2): 141-50. doi: 10.1016/S0960-8966(01)00250-4

43. Liu WF, Huang S, Li YL, Zhang K, Zheng X. Suppressive effect of glycyrrhizic acid against lipopolysaccharide-induced neuroinflammation and cognitive impairment in C57 mice via tolllike receptor 4 signaling pathway. Food Nutr Res 2019; 63: 1516. doi: $10.29219 /$ fnr.v63.1516

44. Triantafilou M, Triantafilou K. The dynamics of LPS recognition: complex orchestration of multiple receptors. J Endotoxin Res 2005; 11(1): 5-11. doi: 10.1179/096805105225006641

45. Zhong W, Chi G, Jiang L, Soromou LW, Chen N, Huo M, et al. p-Cymene modulates in vitro and in vivo cytokine production by inhibiting MAPK and NF-KB activation. Inflammation 2013; 36(3): 529-37. doi: 10.1007/s10753-012-9574-y

\footnotetext{
*Xiujing Dou and Yonggen Zhang

College of Animal Science and Technology

Northeast Agricultural University

Harbin, China.

Tel.: +8645155190840

Fax: +8645155190840

Email: zhangyonggen@sina.com; douxiujing@neau.edu.cn
} 